\title{
Literatures on Dyeing Technique of Supercritical Fluid Carbon Dioxide
}

\author{
Shen-Kung Liao, Pi-Shiun Chang \\ Department of Fiber and Composite Materials, Feng Chia University, Taichung, Chinese Taipei \\ Email:skliao@fcu.edu.tw
}

Received October 9, 2012; revised November 14, 2012; accepted November 30, 2012

\begin{abstract}
The supercritical fluid is used extensively, especially in substance extraction. The extraction of many substances has reached the economic-scale industrial bulk production stage. However, the research on the wastewater-free dyeing technique replacing water as dissolvent is still at a development stage. This study introduced the development situation of supercritical fluid dyeing technique, and described the evolution of stock dyeing, measurement of solubility of dye, studies of dyeing kinetics and instrument application studies, in order to provide related data for relevant studies in further development of this technique.
\end{abstract}

Keywords: Supercritical Fluid; Fluid Density; Solubility Parameter; K/S Value; Equilibrium Dyeing

\section{Introduction}

The application of making fluid into supercritical fluid above critical temperature and critical pressure by heating and pressurizing it, especially supercritical carbon dioxide $\left(\mathrm{Tc}=31^{\circ} \mathrm{C}, \mathrm{Pc}=7.38 \mathrm{bar}\right.$ ), originated from replacing traditional solvent extraction of caffeine from coffee bean or nicotine from tobacco [1,2]. This technique has reached the economic scale of mass production. Relevant studies on using supercritical carbon dioxide for extraction and purification have thus emerged since 1980s, including application to vegetable essential oil extraction $[3,4]$, abstracting lecithin beneficial to human health, extracting $\beta$-carotene and lycopene from tomatoes or producing powder requiring strict particle size distribution and purity in pharmacy, extracting oligomer from polymer [5-8], and application to fluorine-containing polymer polymerization dispersion reaction and gas chromatography technique as dissolvent [9-11]. The application domains have extended continuously, so that the supercritical fluid technique has become an important part of chemical and chemical industry domains.

In the application to fiber and high molecular material, the supercritical carbon dioxide is used to dissolve fluothane sizing agent to size and desize $\mathrm{T} / \mathrm{C}$ blend fabric [12]. The supercritical carbon dioxide is used to dissolve chemical substances. The chemical substances are filled in the substrate to reinforce the physical and chemical properties of material [13]. Austrian scholar Marr [14] and German scholar Werner [15] reviewed related literature publication and technical conditions of using supercriti- cal fluid in extraction processing, and proposed that the phase behavior of supercritical fluid dissolved solute under different PVT (P: pressure, V: volume, T: temperature) conditions is the key factor influencing the extraction effect. They argued that the important factors, such as phase behavior and solubility of solute in supercritical fluid, could be estimated by using the equation of state. Moreover, they listed the important parameters $\mathrm{a}, \mathrm{b}, \mathrm{u}$ and $\mathrm{w}$ of Van der Waals, Soave/Redlich-Kwong and Peng-Robinson equations of state in the application of supercritical fluid. [14] The estimated value accuracy of each equation of state in liquid or solid solute was related to the enthalpy and internal energy of solute and its interaction on fluid. Since Saus and Schollmeyer [16-19] published literatures on using supercritical carbon dioxide dissolved dispersed dyestuff to dye polyester fiber in 1992, there have been a number of studies using supercritical carbon dioxide to dissolve dyed polyester, polyamide or even natural fibers, such as cotton, wool and silk. The carbon dioxide in the application of supercritical fluid is characterized by safety, innocuity, no waste-water pollution, low cost, incombustibility and reusability in dyeing technique. It is an environment-friendly alternate dissolvent, and is very promising in commercial development [20]. This study attempts to review the literatures on applying carbon dioxide to dyeing technique since 1992, and propose important achievements in the literatures to briefly describing the evolution of stock dyeing, solubility of dye, dyeing kinetics and instrumental technique. Related studies can thus obtain information to find out the technological development situation. 


\section{Evolution of Supercritical Fluid Dyeing}

The supercritical carbon dioxide is the most natural and innocuous fluid. The dyeing technique replacing the existing organic solvent by this medium is very advantageous to environmental protection, wastewater treatment and manufacturing cost. Since the supercritical carbon dioxide fluid approximates to gas basically, there will be no more waste discharge when it is used to replace organic liquid to dye hydrophobic fiber, the industrial water, industrial waste, and energy consumption are reduced. In 1982, Chou and Wessinger [21-30] studied the absorbency and swelling capacity of supercritical carbon dioxide for polystyrene, PVC, polycarbonate and PMMA, polypropylene and polyester and polyurethane polymers. They applied the supercritical fluid technique to membrane separation gas mixture or to fill chemical substances in polymer for dyeing. The results showed that the polycarbonate and PMMA with carbonyl $(\mathrm{C}=\mathrm{O})$ have the maximum affinity for carbon dioxide and the most obvious plasticity. Kazarian used FTIR and ATR infrared spectrum analysis results $[31,32]$ to prove that the oxygen atom of carbon dioxide has polar effect on polymer carbonyl. The carbon dioxide was equivalent to the Lewis Pair reacted electron acceptor (acid); thus, using carbon dioxide as dissolvent is very potential in polymer dyeing.

Saus and Schollmeyer [16,33-36] used supercritical carbon dioxide to replace water as dissolvent, schematic diagram of supercritical fluid dyeing as shown Figure 1, for disperse dye to dye polyester fiber in 1992 . The polyester fiber was dyed successfully as the solubility of carbon dioxide for disperse dye, and it was easier than water to permeate in fiber. They claimed that good equalization and fastness of dyeing could be obtained directly without any additive. DeGiorgi [37] compared dyeing polyester fiber by supercritical carbon dioxide with that by water, the result showed that the $\mathrm{K} / \mathrm{S}$ value of polyester fiber dyed by supercritical carbon dioxide as dissolvent at $80^{\circ} \mathrm{C}$ and 240 bar was equivalent to the effect of water dyeing at $120^{\circ} \mathrm{C}$. In addition, Germany began to implement the 5 $10 \mathrm{~L}$ level quantitative test for supercritical dyeing of polyester fiber when literatures were published in 1992, and Bach and Schollmeyer [38,39] increased the scale to $30 \mathrm{~L}$ in 1998, stepping towards an economic scale. At present, the major bottle-neck factor in the technique is that the design of fluid circulation equipments must consider reducing the color difference between the inner and outer faces of dyed fabric.

In 1994, Gebert et al. [19] carried out hydrophobic modification of cotton and wool fiber, and used disperse dye for supercritical carbon dioxide dyeing, but the fastness of dyeing was not ideal. Therefore, Lewis et al. [40,41] used sodium benzoate and polyethylene glycol to modify cotton fiber respectively, and obtained good dyeing effect, but it was not commercialized because the cost was very high and the modification reduced the tearing strength of cotton fabric. In 2000, Liao et al. [36,42,43] used reactive disperse dye in supercritical carbon dioxide phase to dye polyamide fiber. The extraction of pyridine solution proved that the reactive disperse dye could react with the amido at the end of fiber for dyeing, but the dyeing $\mathrm{K} / \mathrm{S}$ value $<9$, yet failing to attain darkening. Afterwards, Schmidt [44] used 2-brom acrylic acid and dichlorobenzene s-triazine to replace C.I. Disperse Yellow 23 dye end group as reactive disperse dye, the wool and silk fiber could be dyed successfully without any preparation, and various dyeing fastnesses were above grade 4 . However, the dyeing duration at 280 bar and $160^{\circ} \mathrm{C}$ should be $4 \mathrm{~h}$ in order to reach $\mathrm{K} / \mathrm{S}$ value of 12 , and the dyeing $\mathrm{K} / \mathrm{S}$ value of cotton fabric was lower than 5 , which was not ideal. Guzel and Akgerman [45] used new type of mordant dye in supercritical carbon dioxide phase to dye wool fiber. Sawada and Ueda [46] proposed that the dyeing mechanism of dyeing wool and silk fibers by acid dye conformed to the Langmuir adsorption behavior in 2004.

In 2007, Fernandez et al. [47-49] added cosolvent methanol in supercritical fluid phase, as the carbon dioxide was Lewis acid in the system, helping the methanol to replace the chlorine atoms of s-triazine reactive disperse dye to generate hydroxymethyl which had etherification reaction with cotton in carbon dioxide phase for dyeing, and the study compared the dyeing capacities of different substituent $\left(\mathrm{Cl} / \mathrm{OCH}_{3} / \mathrm{NH}_{2} / \mathrm{F}\right)$ dyes in supercritical carbon dioxide, the dyestuff fixing rate was still higher than $75 \%$ after solution extraction. However, the methanol has optic neurotoxicity and volatility problems, further tests should be carried out to determine a safe and innoxious cosolvent. In 2000, Bilgehan [50] used mordanting to compare the mordanting effects of different dyes chelated by $\mathrm{Cr}(\mathrm{III}), \mathrm{Al}(\mathrm{III}), \mathrm{Cu}(\mathrm{II}), \mathrm{Fe}(\mathrm{II})$ and $\mathrm{Sn}(\mathrm{II})$, and further compared the differences among the colors of three dyes mordanted by different metal ions. The washing fastness was above grade 4 , but the dyeing situation was not digitized. In terms of heavy metal mordanting, the metal ion should be mixed with a small amount of water to help the mordant dye adsorb to the fiber surface. In 2004, Ueda et $a l$. [51,52] used reverse micelle to dissolve acid dye in a micro amount of water, and added grade 4 ammonium salt cosolvent in acid dye solution to make it disperse in supercritical carbon dioxide phase stably to overcome the insolubility of acid dye in carbon dioxide. The wool and silk fibers could be dyed at $40^{\circ} \mathrm{C}-55^{\circ} \mathrm{C}$, and the fiber extracting solution was tested by UV spectrum. The saturated amount of dyeing at $40^{\circ} \mathrm{C}$ was $1 \times 10^{-5} \mathrm{~mol} / \mathrm{g}$ fiber (wool) and $3 \times 10^{-5} \mathrm{~mol} / \mathrm{g}$ (silk) respectively, and the apparent concentration K/S value was 20 - 30 .

In terms of polypropylene fiber, which cannot be dyed by traditional water bath, Bach and Schollmeyer $[53,54]$ 


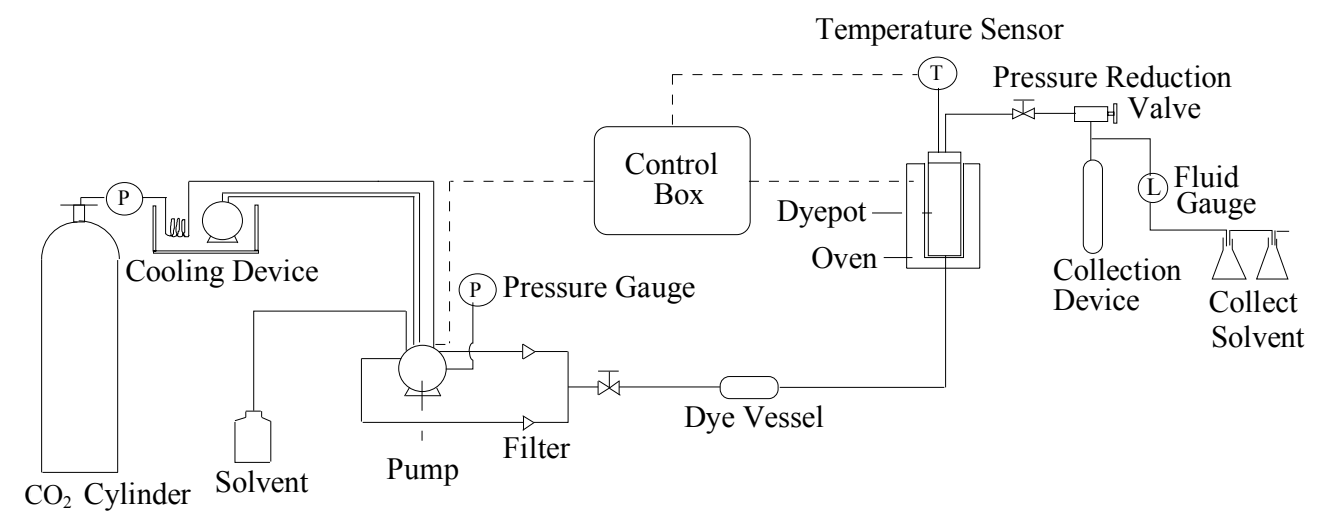

Figure 1. Schematic diagram of supercritical fluid dyeing [36].

found that the $\mathrm{Tg}$ point temperature of polypropylene fiber decreased obviously when the carbon dioxide pressure was higher than 250 bar. Thus, the supercritical carbon dioxide could plastify polypropylene fiber effectively, and help the disperse dye to penetrate into the fiber to dye it. Bach et al. indicated that the heterocyclic disperse dye had better dyeing effect on polypropylene fiber. Liao et al. [55] studied $450 \mathrm{~d} \times 500 \mathrm{~d}$ polypropylene fabric, the microscopical analysis of optical slicing showed the disperse dye in anthraquinone structure could penetrate into the fiber inside yarn diffusely, whereas the water bath dyeing could not make it. It proved the potential of supercritical carbon dioxide in dyeing polypropylene fiber, but the fine denier polypropylene fiber dyeing should be overcome.

In sum, for the tests of dye compatibility and multidye color matching, as the research on dissolving dye by supercritical fluid require a lot of research data, and the dyeing dissipation mechanism of dye is not yet understood completely, there should be more complete research data.

\section{Dye Solubility of Supercritical Fluid Phase}

As the key in the success of supercritical fluid dyeing is the solubility and dispersion particle size of dye in supercritical carbon dioxide phase, according to Gibbs phase rule [1], the control variables of two component system are temperature $\mathrm{T}$, pressure $\mathrm{P}$ and mole fraction $\mathrm{x}$ of solute to carbon dioxide. The three-dimensional three-phase diagram is formed from dye three-phase diagram and carbon dioxide three-phase diagram according to the $\mathrm{P}, \mathrm{T}$ and $\mathrm{x}$ conditions change $[56,57]$. A condition is fixed parallel to the P-x or T-x plane for cutting, so as to obtain the phase equilibrium diagrams of different dye strengthspressures and different dye strengths-temperatures. Therefore, the pressure and temperature conditions reaching the phase of uniform dye and carbon dioxide dispersion are selected. The dyeing tank is mounted with a high pressure proof transparent window, and the dye solubility can be tested. In 1996, Akgerman and Bae et al. [58-60] studied the solubility of disperse dye in supercritical carbon dioxide at $353^{\circ} \mathrm{K}-393^{\circ} \mathrm{K}$ and $30 \mathrm{MPa}$. Their result showed that the solubility of dye could be increased by at most 100 times when the carbon dioxide pressure increased from $15 \mathrm{MPa}$ to $30 \mathrm{MPa}$. In order to predict the dye solubility, the parameter values that meet the equation result precisely must be obtained according to experimental values based on the equation of state meeting the supercritical fluid dyeing condition. The equation of the state designed for the solvent fluid density [61-63] is free from the critical behavior of fluid, only considering the temperature, pressure and fluid density. The solubility can be calculated by obtaining appropriate parameter values from least square method regression of experimental value, but the considerable error values will result in inaccurate predicted value. In 2005, Kawi et al. [64] gathered the data of solubility of disperse dye in supercritical carbon dioxide phase of 1996-2004, and used the solubility data in four density-based models to determine a better and simpler equation to predict the solubility value of dye. The experimental result showed that the equation $\ln y_{2}=a_{0}+a_{1} \ln \rho+a_{2} / \mathrm{T}$ proposed by Crastil is more consistent with the result of measured value. However, for most of data, there were $12 \%$ - $40 \%$ error values between the calculated values and the actual values. In 2000, Bae et al. $[59,60]$ compared the measured solubility of C.I. Disperse Blue 3 and Blue 79 dyes at $323.7^{\circ} \mathrm{K}-413.7^{\circ} \mathrm{K}$ and $100-305$ bar with the solubility computing equation of dilatant fluid state equation, and the obtained solubility value was very accurate as shown Table $\mathbf{1}$.

In 2004, Ueda et al. [65] continued the reverse micelle experiment, and mixed pentaethylene glycol n-octyl ether with a small amount of surfactant to cover acid dye water solution. They measured the acid dye reverse micelle solubility in supercritical carbon dioxide, and found that the stability of reverse micelle phase in the carbon dioxide was related to the carbochain length of alcohol surfactant. The most stable dispersed state could be obtained 
using 1-pentanol. The dispersion stability decreased as the temperature rose and the pressure dropped, increasing the concentration of 1-pentanol was helpful to increasing the dispersion stability. The increase in the carbon dioxide pres- sure was helpless to the solubility of acid dye reverse micelle, which was different from the trend of disperse dye solubility increasing with pressure. It is ascribed to that the acid dye has no affinity for carbon dioxide.

As the solubility of supercritical fluid dye cannot be obtain by concentration accurately as that in water phase, it is required to develop more refined calculation to calculate the partition ratio between fiber and carbon dioxide phase, so as to help with the color repeatability in the future quantification.

\section{Research on Supercritical Fluid Dyeing Kinetics}

In order to further develop supercritical fluid dyeing technique for quantification, a theoretical model of distribution coefficient among the dye, fiber and supercritical carbon dioxide must be built. The diffusivity and equilibrium dyeing amount of dye in fiber at fixed temperature and pressure should be obtained. In 2002, Park and Bae [66] placed the dye (C.I. Disperse Red 60) exceeding the carbon dioxide solubility value in the dyeing tank directly for supercritical fluid dyeing of polyester fiber. The supercritical carbon dioxide was set as dilatant fluid, and the carbon dioxide phase was two-component

Table 1. Measurement of dye solubility in supercritical carbon dioxide $[59,60]$.

\begin{tabular}{|c|c|c|c|c|c|c|c|}
\hline \multicolumn{2}{|c|}{$323.7^{\circ} \mathrm{K}$} & \multicolumn{2}{|c|}{$353.7^{\circ} \mathrm{K}$} & \multicolumn{2}{|c|}{$383.7^{\circ} \mathrm{K}$} & \multicolumn{2}{|c|}{$413.7^{\circ} \mathrm{K}$} \\
\hline P (bar & $\left.10^{6} \mathrm{y}_{2}\right)$ & P (bar & $\left.10^{6} y_{2}\right)$ & $\mathrm{P}$ (bar & $\left.10^{6} \mathrm{y}_{2}\right)$ & $\mathrm{P}$ (bar & $\left.10^{6} \mathrm{y}_{2}\right)$ \\
\hline \multicolumn{8}{|c|}{ C.I. Disperse Blue 3} \\
\hline 105.1 & 6.119 & 106.5 & 0.680 & 106.2 & 0.821 & 106.8 & 0.725 \\
\hline 157.8 & 10.13 & 158.7 & 20.02 & 140.3 & 8.930 & 142.1 & 3.005 \\
\hline 216.1 & 16.08 & 216.8 & 35.76 & 181.8 & 19.85 & 187.2 & 13.65 \\
\hline 261.7 & 15.78 & 245.8 & 16.16 & 226.5 & 23.34 & 227.2 & 27.64 \\
\hline 301.5 & 14.32 & 275.9 & 30.07 & 266.0 & 28.20 & 283.7 & 42.84 \\
\hline- & - & 318.1 & 41.92 & 318.1 & 38.19 & 329.8 & 63.57 \\
\hline \multicolumn{8}{|c|}{ C.I.Disperse Blue 79} \\
\hline 101.9 & 0.344 & 99.2 & 0.177 & 99.9 & 0.008 & - & - \\
\hline 148.1 & 1.091 & 149.2 & 0.494 & 152.7 & 0.007 & - & - \\
\hline 198.9 & 2.039 & 196.7 & 1.407 & 202.0 & 0.698 & - & - \\
\hline 253.9 & 4.378 & 253.9 & 4.639 & 255.3 & 3.381 & - & - \\
\hline 301.3 & 5.669 & 304.7 & 7.515 & 305.1 & 9.193 & - & - \\
\hline
\end{tabular}

fluid system of dye dissolved in carbon dioxide. The polyester fiber was three-component system of carbon dioxide, dye and fiber, and used Flory-Huggins theory. The activity coefficient of component $k$ is:

$$
\begin{aligned}
R T \ln \gamma_{k}= & v_{k} \sum \sum\left(A_{i k}-A_{i j}\right) \Phi_{i} \Phi_{j} \\
& +R T\left(\ln \Phi_{k} / x_{k}+1-\Phi_{k} / x_{k}\right)
\end{aligned}
$$

The distribution coefficient value of dye in polyester fiber and carbon dioxide phase in dyeing equilibrium is:

$$
K_{2}=y_{2} / x_{2}=\gamma_{2}^{P E T} / \gamma_{2}^{\text {super }}
$$

Three-component system of polyester fiber, carbon dioxide and dye:

$$
\begin{aligned}
& R T \ln \gamma_{2}=v_{2}\left[\left(A_{12} \Phi_{1}^{2}+A_{23} \Phi_{3}^{2}\right)+\left(A_{12}-A_{13}+A_{23}\right) \Phi_{1} \Phi_{2}\right] \\
& +R T \ln \Phi_{2} / x_{2}+1-\Phi_{2} / x_{2} \\
& \text { where } A_{12}=\left(\delta_{d 1}-\delta_{d 2}\right)^{2}-\beta_{12}, A_{13}=\left(\delta_{d 1}-\delta_{d 3}\right)^{2}-\beta_{13} \text {, } \\
& A_{23}=\left(\delta_{d 2}-\delta_{d 3}\right)^{2}-\beta_{23}
\end{aligned}
$$

According to the above theory, Sandler cited the parameter values in literatures [67] to estimate the interaction parameter values of dye, carbon dioxide and polyester fiber $\beta_{12}, \beta_{23}$ and $\beta_{13}$. He used ultraviolet spectrograph to measure the dye extracting solution on the fiber to obtain the actual amount of dyeing, and compared it with the amount of dyeing calculated by the above theory. It was found that the amount of dyeing calculated by substituting the $\beta_{23}$ interaction parameter estimated using three-component system theory in the aforesaid equation matched the actual value very well. This suggests that the distribution coefficient increased with the pressure, but decreased as the temperature rose.

In 2004, Ferri [68,69] substituted the measured dye solubility value in the equation of state proposed by $\mathrm{Fu}-$ nazukuri et al. [70] and the semiempirical equation of state simulating Langmuir absorption, in order to obtain the distribution coefficient between polyester fiber and supercritical carbon dioxide of C.I. Disperse Orange 3, C.I. Disperse Blue 79 and Solvent Brown 1 dyes [71]. The distribution coefficient was defined as $K=\omega_{i}^{p} / \omega_{i}^{f}$, where $\omega_{i}^{p}$ is the mass fraction of dye in fiber phase and $\omega_{i}^{f}$ is the mass fraction of dye in fluid phase. The obtained distribution coefficient varied with the dye structure. Generally, the distribution coefficient of $373.2^{\circ} \mathrm{K}$ $393.2^{\circ} \mathrm{K}$ and 160 bar -180 bar is higher than 1500 , which is different from that of Bae et al. Moreover, the coefficient also decreased as the pressure increased, which was contradictory to the Bae trend. Ferri et al. suggested that increasing the density (pressure) of carbon dioxide could enhance the plasticity of fluid on fiber, so that the dye on the polyester fiber would return to the carbon dioxide phase and the distribution coefficient decreased. This study found that the dye on the polyester fiber may return to the carbon dioxide phase when different dye mole- 
cules are in different pressure ranges (above 220 bar) due to the difference in molecular size and the steric hindrance effect of chemical structure. The result of comparison between measured distribution coefficient and estimated distribution coefficient using empirical equation showed that the mean error value calculated by five-parameter semiempirical equation is lower than $6.6 \%$.

The above studies are fundamental research on dyeing. As limited to equipment measurement technique, there are few literatures on the calculation of diffusion behavior and diffusivity of supercritical fluid dye in fiber, thus deserving further study.

\section{Application of Instrumental Technique}

In 1996, Kazarian et al. used infrared spectrometer FTIR and AT R and supercritical dyeing equipment with window to observe the plasticity of supercritical carbon dioxide on different polymer membranes $[31,32]$, thus initiating the direct application of instrumental analysis. In 2005, Kazarian [72] used Raman infrared spectrometer to observe the diffusion behavior of C.I. Disperse Yellow 23 dye in PET fiber. The aberrations resulted from object lens entry refractive index and the optical refraction in the oil bath similar to object lens was eliminated. Different Raman spectra absorption peak intensity values between surface and center point in the fiber diameter could be obtained. The variation in intensity of Raman spectra absorption peak was observed at different times (absorption peak intensity was directly proportional to dye strength). The relationship between Raman spectra absorption peak intensity and time square root could thus be obtained. The straight slope value was converted into the diffusivity $3.5 \times 10^{-13} \mathrm{~m}^{2} / \mathrm{s}$ of Disperse Yellow 23 dye in the supercritical carbon dioxide, and compared with the $1.5 \times$ $10^{-13} \mathrm{~m}^{2} / \mathrm{s}$ calculated by Sicardi et al. [73] The results were very close. Therefore, a method was provided for using instrument to measure the diffusivity of supercritical fluid dye.

\section{Conclusion}

Supercritical fluid means that the operating temperature and pressure have exceeded the critical temperature and critical pressure of medium and the fluid has a lot of unique physic-chemical properties in supercritical state, such as low viscosity as gas, high density as liquid, high diffusivity, low surface tension and solubility. Operation of supercritical fluid carbon dioxide can be changed by controlling the temperature and pressure, even co-solvent. However, the research on the supercritical fluid carbon dioxide replacing water as dissolvent is still at a development stage. This paper has reviewed literatures on the development of supercritical carbon dioxide dyeing technique. It did not fully probe into all literatures on super- critical fluid dyeing, because the supercritical fluid dyeing uses the data from literatures of chemical phase equilibrium and chemical materials, fiber and dyeing kinetics, which could only be briefly mentioned in a summary paper. Furthermore, the evaluation of absorption isotherm should be studied on the future development of supercritical fluid carbon dioxide. The brief introduction on the existing circumstances of development can provide an understanding of the development of supercritical fluid dyeing technique for further studies.

\section{REFERENCES}

[1] M. A. McHugh and V. J. Krukonis, "Supercritical Fluid Extraction: Principles and Practice," 2nd Edition, Butterworth-Heinemann Press, Boston, 1994.

[2] Philip Morris Inc., United States Patent No. 2143388, 1971.

[3] J. C. de la Fuente, B. T. Fornari, E. A. Brignole and S. B. Bottini, Proceedings of the 3rd International Sympo- sium on Supercritical Fluids, Strasbourg, 1994, p. 289.

[4] T. Klein and S. Schulz, "Measurement and Model Prediction of Vapor-Liquid Equilibria of Mixtures of Rapseed Oil and Supercritical Carbon Dioxide," Industrial Engineering \& Chemistry Research, Vol. 28, No. 7, 1989, pp. 1073-1081. doi:10.1021/ie00091a029

[5] E. Cadoni, M. R. DeGiorgi and G. Poma, "Supercritical Extraction of Lycopene and $\beta$-Carotene from Ripe Tomatoes," Dyes and Pigments, Vol. 44, No. 1, 1999, pp. 27-32. doi:10.1016/S0143-7208(99)00065-0

[6] K. M. Scholsky, "Process Polymers with Supercritical Fluids," Chemistry Technology, Vol. 17, No. 12, 1987, pp. 750-757.

[7] N. J. Cotton, K. D. Bartle and C. J. Dowle, "Rate and Extent of Supercritical Fluid Extraction of Additives from Polpropylene: Diffusion, Solubility and Matrix Effects," Journal of Applied Polymer Science, Vol. 48, No. 9, 1993, pp. 1607-1619. doi:10.1002/app.1993.070480913

[8] G. Montero, D. Hinks and J. Hooker, "Reducing Problems of Cyclic Trimer Deposits in Supercritical Carbon Dioxide Polyester Dyeing Machinery," Journal of Supercritical Fluids, Vol. 26, No. 1, 2003, pp. 47-54. doi:10.1016/S0896-8446(02)00187-0

[9] M. Roth, "Thermodynamics of Modifier Effects in Supercritical Fluid Chromatography," Journal of Physical Chemistry, Vol. 100, No. 6, 1996, pp. 2372-2375. doi:10.1021/jp952450x

[10] D. A. Canelas, D. E. Betts and J. M. DeSimone, "Dispersion Polymerization of Styrene in Supercritical Carbon Dioxide: Importance of Effective Surfactants," Macromolecules, Vol. 29, No. 8, 1996, pp. 2818-2821. doi:10.1021/ma951642n

[11] J. M. DeSimone, E. Maury, J. B. McClain and J. R. Combes, "Dispersion Polymerization in Supercritical Carbon Dioxide," Science, Vol. 265, No. 5170, 1994, pp. 356-359. doi:10.1126/science.265.5170.356

[12] L. E. Bowman, C. G. Caley and J. L. Fulton, "Sizing and 
Desizing Polyester/Cotton Blend Yarns Using Liquid Carbon Dioxide," Textile Research Journal, Vol. 66, No. 12, 1996, pp. 795-802. doi: $10.1177 / 004051759606601208$

[13] E. S. Demessie and J. J. Morrell, "Impregnating Porous Solids Using Supercritical $\mathrm{CO}_{2}$," Chemtech, Vol. 28, No. 3, 1998, pp. 12-18.

[14] R. Marr and T. Gamse, "Use of Supercritical Fluids for Different Processes Including New Developments: A Review," Chemical Engineering and Processing, Vol. 39, No. 1, 2000, pp. 19-28. doi:10.1016/S0255-2701(99)00070-7

[15] W. H. Hauthal, "Advances with Supercritical Fluids (Review)," Chemosphere, Vol. 43, No. 1, 2001, pp. 123-135. doi:10.1016/S0045-6535(00)00332-5

[16] W. Saus, "Dyeing of Technical Fibers in Supercritical $\mathrm{CO}_{2}$," Textile-Symposium, Frankfurt, 1992.

[17] D. Knittel, W. Saus and E. Schollmeyer, "Application of Supercritical Carbon Dioxide in Finishing Process," Journal of Textile Institute, Vol. 84, No. 4, 1993, pp. 534-552. doi:10.1080/00405009308658986

[18] W. Saus, D. Knittel and E.Schollmeyer, "Water-Free Dyeing of Synthetic Material-Dyeing in Supercritical $\mathrm{CO}_{2}$," International Textile Bullteins Trends, Vol. 39, 1994, pp. 99-101.

[19] B. Gebert, W. Saus, D. Knittel and H. J. Buschmann, "Dyeing Natural Fibers with Disperse Dyes in Supercritical Carbon Dioxide," Textile Research Journal, Vol. 67, No. 7, 1994, pp. 371-374. doi:10.1177/004051759406400701

[20] P. Schelbli and W. Scklenker, "Dyeing in Supercritical Carbon Dioxide-An Environmental Quantum Leap in Textile Processing," Chemiefasern/Textilindustrie English, Vol. 43, 1994, pp. 64-65.

[21] W. Chou and E. J. Kramer, "Effects of High Pressure $\mathrm{CO}_{2}$ on the Glass Transition Temperature and Mechanical Properties of Polystyrene," Journal of Polymer Science, Vol. 20, No. 8, 1982, pp. 1371-1384.

[22] J. S. Chiou, J. W. Barlow and D. R. Paul, "Plasticization of Glassy Polymers by $\mathrm{CO}_{2}$," Journal of Applied Polymer Science, Vol. 30, No. 6, 1985, pp. 2633-2642. doi:10.1002/app.1985.070300626

[23] R. G. Wessinger and M. E. Paulaitis, "Swelling and Sorption in Polymer- $\mathrm{CO}_{2}$ Mixture at Elevated Pressures," Journal of Polymer Physics Part B: Polymer Physics, Vol. 25, No. 12, 1987, pp. 2497-2510. doi:10.1002/polb.1987.090251206

[24] Y. T. Shieh, J. H. Su and W. D. Spall, "Interaction of Supercritical Carbon Dioxide with Polymers, I: Crystalline Polymers," Journal of Applied Polymer Science, Vol. 59, No. 4, 1996, pp. 695-705. doi:10.1002/(SICI)1097-4628(19960124)59:4<695::AIDAPP15>3.0.CO;2-P

[25] S. H. Chang and J. J. Shim, "Phase Equilibria of Supercritical Fluids-Polymer Systems," Journal of Supercritical Fluids, Vol. 13, No. 1-3, 1998, pp. 113-119. doi:10.1016/S0896-8446(98)00042-4

[26] G. Mensitieri, G. Guerra and A. Apicella, "Low Temperature Melting Behavior of $\mathrm{CO}_{2}$ Crystallized Modified
PETs," Polymer Engineering and Science, Vol. 35, No. 3, 1995, pp. 506-512. doi:10.1002/pen.760350608

[27] B. J. Briscoe and C. T. Kelly, "The Plasticization of a Polyurethane by Carbon Dioxide at High Pneumatic Stresses," Polymer, Vol. 36, No. 16, 1995, pp. 3099-3102. doi:10.1016/0032-3861(95)97871-C

[28] K. Mizoguchi, T. Hirose and Y. Kamiya, "CO Crystallization of Poly(ethylene terephthalate)," Polymer, Vol. 28, No. 8, 1987, pp. 1298-1302. doi:10.1016/0032-3861(87)90441-1

[29] M. J. Drews and C. Jordan, "The Effect of Supercritical $\mathrm{CO}_{2}$ Dyeing Conditions on the Morphology of Polyester Fibers," Textile Chemist and Colorist, Vol. 92, No. 3, 1998, pp. 2008-2012.

[30] M. S. Sfiligoj and P. Zipper, "WAXS Analysis of Structural Changes of PET Fibers Induced by Supercritical Fluid Dyeing," Colloid Polymer Science, Vol. 276, No. 2, 1998, pp. 144-151. doi:10.1007/s003960050222

[31] S. G. Kazarian, M. F. Vincent and C. A. Eckert, "Specific Intermolecular Interaction of Carbon Dioxide with Polymers", Journal of American Chemical Society, Vol. 118, No. 7, 1996, pp. 1729-1736. doi:10.1021/ja950416q

[32] S. G. Kazarian, N. H. Brantely and C. A. Eckert, "In situ Spectroscopy of Polymers Subjected to Supercritical $\mathrm{CO}_{2}$ : Plasticization and Dye Impregnation," Applied Spectroscopy, Vol. 51, No. 4, 1997, pp. 491-494.

[33] W. Saus and E. Schollmeyer, "Dyeing of Textiles on Supercritical Carbon Dioxide," Textile Research Journal, Vol. 63, No. 3, 1993, pp. 135-142. doi: $10.1177 / 004051759306300302$

[34] D. Knittel and E. Schollmeyer, "Dyeing from Supercritical $\mathrm{CO}_{2}$-Fastness of Dyeing," Melliand English, Vol. 23, 1994, pp. 99-100.

[35] T. T. Ngo, C. L. Liotta, C. A. Eckert and S. G. Kazarian, "Supercritical Fluid Impregnation of Different Azo-Dyes into Polymer: In situ UV/Vis Spectroscopic Study," Journal of Supercritical Fluids, Vol. 27, No. 2, 2003, pp. 215 221.

[36] S. K. Liao, Y. C. Ho and P. S. Chang, "Dyeing of Nylon 66 with a Disperse-reactive Dye Using Supercritical Carbon Dioxide," Journal of the Society of Dyers and Colourists, Vol. 116, No. 12, 2000, pp. 403-407.

[37] M. R. de Giorgi, E. Cadoni, D. Maricca and A. Piras, "Dyeing Poly- ester Fibers with Disperse Dyes in Supercritical $\mathrm{CO}_{2}$," Dyes and Pigments, Vol. 45, No. 1, 2000, pp. 7579. doi:10.1016/S0143-7208(00)00011-5

[38] E. Bach, E. Cleve and E. Schollmeyer, "Experience with the UHDE $\mathrm{CO}_{2}$-Dyeing Plant on Techanical Scale, Part I: Optimization Steps of the Pilot Plant and First Dyeing Results," Melliand International, Vol. 3, 1998, pp. 192-194.

[39] E. Bach, E. Cleve, E. Schollmeyer and T. Vardag, "Experiences with the UHDE $\mathrm{CO}_{2}$-Dyeing Plant on techanical Scale, Part II: Concepts for the Development of the Pilot Plant in Respect of a Scaling up of the Machine," Melliand International, Vol. 2, 1999, pp. 165-168.

[40] A. S. Ozcan, A. A. Clifford and D. M. Lewis, "Dyeing of Modified Cotton Fibers with Disperse Dyes from Supercritical Carbon Dioxide," Journal of the Society of Dyers 
and Colourists, Vol. 114, No. 5-6, 1998, pp. 169-173. doi:10.1111/j.1478-4408.1998.tb01977.x

[41] P. L. Belneate, A. Castelli and A. Seves, "Dyeing of Cotton in Supercritical Carbon Dioxide," Dyes and Pigments, Vol. 39, No. 4, 1998, pp. 335-340. doi:10.1016/S0143-7208(98)00016-3

[42] S. K. Liao, "Dyeing of Microdenier Polyester Fabric in Supercritical Carbon Dioxide," Indian Journal of Fiber \& Textile Research, Vol. 30, No. 3, 2005, pp. 324-330.

[43] M. van der Kraan, M. V. Fernandez-Cid, G. F. Woerlee, W. J. T. Veugelers and G. J. Witkamp, "Dyeing of Natural and Synthetic Textiles in Supercritical Carbon Dioxide with Disperse Reactive Dyes," Journal of Supercritical Fluids, Vol. 40, No. 3, 2007, pp. 470-476.

[44] A. Schmidt, E. Bach and E. Schollmeyer, "The Dyeing of Natural Fibres with Reactive Disperse Dyes in Supercritical Carbon Dioxide," Dyes and Pigments, Vol. 56, 2003, pp. 27-35. doi:10.1016/S0143-7208(02)00108-0

[45] B. Guzel and A. Akgerman, "Mordant Dyeing of Wool by Supercritical Processing," Journal of Supercritical Fluids, Vol. 18, No. 3, 2000, pp. 247-252. doi:10.1016/S0896-8446(00)00065-6

[46] K. Sawada and M. Ueda, "Evaluation of Dyeing Mechanism of an Acid Dye on Protein Fibers in Supercritical Carbon Dioxide," Dyes and Pigments, Vol. 63, No. 1, 2004, pp. 77-81. doi:10.1016/j.dyepig.2004.01.008

[47] M. V. Fernandez, J. van Spronsen, G. F. Woerlee and G. J. Witkamp, "A Significant Approach to Dye Cotton in Supercritical Carbon Dioxide with Fluorotriazine Reactive Dyes," Journal of Supercritical Fluids, Vol. 40, No. 3, 2007, pp. 477-484.

[48] M. van der Kraan, M. V. Fernandez and G. F. Woerlee, "Dyeing of Natural and Synthetic Textiles in Supercritical Carbon Dioxide with Disperse Reactive Dyes," Journal of Supercritical Fluids, Vol. 40, No. 3, 2007, pp. 470-476. doi:10.1016/j.supflu.2006.07.019

[49] M. V. Fernandez, M. van der Kraan and W. J. Veugelers, "Kinetics Study of a Dichlorotriazine Reactive Dye in Supercritical Carbon Dioxide," Journal of Supercritical Fluids, Vol. 32, No. 1-3, 2004, pp. 147-152. doi:10.1016/j.supflu.2004.03.002

[50] B. Guzel and A. Akgerman, "Mordant Dyeing of Wool by Supercritical Processing," Journal of Supercritical Fluids, Vol. 18, No. 3, 2000, pp. 247-252. doi:10.1016/S0896-8446(00)00065-6

[51] J. H. Jun, K. Sawada and M. Ueda, "Application of Perfluoropolyether Reverse Micelles in Supercritical $\mathrm{CO}_{2}$ to Dyeing Process," Dyes and Pigments, Vol. 61, No. 1, 2004, pp. 17-22. doi:10.1016/j.dyepig.2003.08.003

[52] K. Sawada and M. Ueda, "Evaluation of the Dyeing Mechanism of an Acid Dye on Protein Fibers in Supercritical $\mathrm{CO}_{2}$," Dyes and Pigments, Vol. 63, No. 1, 2004, pp. 77-81. doi:10.1016/i.dyepig.2004.01.008

[53] E. Bach and E. Schollmeyer, "The Dyeing of Polypropylene Fibers in Supercritical Carbon Dioxide, Part I: Thermo-Mechanical Properties of Polyolefin Fibers after Treatment in $\mathrm{CO}_{2}$ under Dyeing Conditions," Journal of Textile Institute, Vol. 89, 1998, pp. 647-656.
[54] E. Bach and E. Schollmeyer, "The Dyeing of Polypropylene Fibers in Supercritical Carbon Dioxide, Part II: The Influence of Dye Structure on the Dyeing of Fabrics and on Fastness Properties," Journal of Textile Institute, Vol. 89, 1998, pp. 657-668.

[55] S. K. Liao and P. S. Chang, "Dyeing of Polypropylene Fibers with Disperse Dyes by Supercritical Carbon Dioxide," Journal of Textile Machinery Society of Japan, Vol. 46, No. 4, 2000, pp. 123-129.

[56] J. H. Noggle, "Physical Chemistry," 2nd Edition, Scott and Foresman Company Press, Glenview, 1989.

[57] R. Koningsveld and G. A. M. Diepen, "Supercritical Phase Equilibria Involving Solids," Fluid Phase Equilibria, Vol. 10, No. 2-3, 1983, pp. 159-172. doi:10.1016/0378-3812(83)80031-4

[58] B. Guzel and A. Akgerman, "Solubility of Disperse and Mordant Dyes in Supercritical Carbon Dioxide," Journal of Chemical Engineering Data, Vol. 44, No. 1, 1999, pp. 83-85. doi:10.1021/je980157v

[59] J. W. Lee, M. W. Park and H. K. Bae, "Measurement and Correlation of Dye Solubility in Supercritical Carbon Dioxide," Fluid Phase Equilibria, Vol. 173, No. 2, 2000, pp. 277-284. doi:10.1016/S0378-3812(00)00404-0

[60] J. W. Lee, M. W. Park and H. K. Bae, "Measurement and Correlation of Dye Solubility in Supercritical Carbon Dioxide," Fluid Phase Equilibria, Vol. 179, No. 1-2, 2001, pp. 387-394. doi:10.1016/S0378-3812(01)00409-5

[61] J. Chrastil, "Solubility of Solids and Liquids in Supercritical Gases," Journal of Physical Chemistry, Vol. 86, No. 15, 1982, pp. 3016-3021. doi:10.1021/j100212a041

[62] K. D. Bartle, A. A. Clifford, S. A. Jafar and G. F. Shilstone, "Solubilities of Solids and Liquids of Low Volatility in Supercritical Carbon Dioxide," Journal of Physical Chemistry Reference Data, Vol. 20, No. 4, 1991, pp. 713756. doi:10.1063/1.555893

[63] J. Mendez-Santiago and A. S. Teja, "The Solubility of Solids in Supercritical Fluids," Fluid Phase Equilibria, Vol. 158-160, 1999, pp. 501-510. doi:10.1016/S0378-3812(99)00154-5

[64] Z. Huang, Y. H. Guo, G. B. Sun and S. Kawi, "Representing Dyestuff Solubility in Supercritical Carbon Dioxide with Several Density Based Cprrelations," Fluid Phase Equilibria, Vol. 236, No. 1-2, 2005, pp. 136-145. doi:10.1016/j.fluid.2005.07.012

[65] K. Sawada, T. Takagi and M. Ueda, "Solubilization of Ionic Dyes in Supercritical Carbon Dioxide: A Basic Study for Dyeing in Non-Aqueous Media," Dyes and Pigments, Vol. 60, No. 2, 2004, pp. 129-135. doi:10.1016/S0143-7208(03)00146-3

[66] M. W. Park and H. K. Bae, "Dye Distribution in Supercritical Dyeing with Carbon Dioxide," Journal of Supercritical Fluids, Vol. 22, No. 1, 2002, pp. 65-73. doi:10.1016/S0896-8446(01)00102-4

[67] S. I. Sandler, "Models for Thermodynamics and Phase Equilibria Calculations," Marcel Dekker, New York, 1996.

[68] A. Ferri, M. Banchero, L. Manna and S. Sicardi, "An Experimental Technique for Measuring High Solubilities of 
Dyes in Supercritical Carbon Dioxide," Journal of Supercritical Fluids, Vol. 30, No. 1, 2004, pp. 41-49. doi:10.1016/S0896-8446(03)00114-1

[69] A. Ferri, M. Banchero, L. Manna and S. Sicardi, "A New Correlation of Solubilities of Azoic Compounds and Anthraquinone Derivatives in Supercritical Carbon Dioxide," Journal of Supercritical Fluids, Vol. 32, No. 1-3, 2004, pp. 27-35. doi:10.1016/i.supflu.2003.12.013

[70] T. Funazukuri, C. Y. Kong and S. Kagei, "Infinite Dilution Binary Diffusion Coefficient, Partition Ratio, and Partial Molar Volume for Ubiquinone CoQ10 in Supercritical Carbon Dioxide," Industrial Engineering Chemical Research, Vol. 41, No. 11, 2002, pp. 2812-2818. doi:10.1021/ie0109096
[71] A. Ferri, M. Banchero, L. Manna and S. Sicardi, "Dye Uptake and Partition Ratio of Disperse Dyes between a PET Yarn and Supercritical Carbon Dioxide," Journal of Supercritical Fluids, Vol. 37, No. 1, 2006, pp. 107-114. doi:10.1016/j.supflu.2005.07.001

[72] O. S. Fleming, S. G. Kazarian, E. Bach and E. Schollmeyer, "Confocal Raman Study of Poly(Ethylene Terephthalate) Fibres Dyed in Supercritical Carbon Dioxide: Dye Diffusion and Polymer Morphology," Polymer, Vol. 46, No. 9, 2005, pp. 2943-2949. doi:10.1016/i.polymer.2005.02.067

[73] S. Scardi, L. Manna and M. banchero, Industrial Engineering Chemical Research, Vol. 39, 2000, p. 4707. 